\title{
Validity of an On-Field Readaptation Program Following a Hamstring Injury in Professional Soccer
}

\author{
Sergio Jiménez-Rubio, Archit Navandar, Jesús Rivilla-García, and Victor Paredes-Hernández
}

\begin{abstract}
Context: Despite the presence of various injury prevention programs, the rate of hamstring injuries and reinjuries is increasing in soccer, warranting the need for a soccer-specific rehabilitation program. Objective: To develop and validate a new, functional onfield program for the rehabilitation and readaptation of soccer players after a hamstring strain injury through a panel of experts; and determine the usefulness of the program through its application in professional soccer players. Design: A 13-item program was developed, which was validated by a panel of experts and later applied to professional soccer players. Setting: Soccer training ground. Participants: Fifteen strength and conditioning and rehabilitation fitness coaches with a professional experience of 15.40 (1.57) years in elite clubs and national teams in Europe validated the program. The program was later applied to 19 professional soccer players of the Spanish First Division (La Liga). Interventions: Once a player sustained a clinically diagnosed injury, the player would first be subject to mobilization and strengthening exercises in the gym after undergoing treatment by percutaneous needle electrolysis. The player would then complete an on-field readaptation program consisting of 13 drills arranged in a progressive manner in terms of complexity. The drills integrated various aspects of repeated sprint abilities, retraining and reeducation of biomechanical patterns, and neuromuscular control of the core and lower limbs. Main Outcome Measures: Aiken's V for each item of the program and number of days taken by the players to return to play. Results: The experts evaluated all items of the program very highly, as seen from Aiken's V values between 0.78 and $0.98(0.63-0.99)$ for all drills, while the return to play was in 22.42 (2.32) days. Conclusion: This program has the potential to help a player suffering from a hamstring strain injury to adapt to real-match conditions in the readaptation phase through the application of sports-specific drills that were very similar to the different injury mechanisms.
\end{abstract}

Keywords: return to play, injury management, functional rehabilitation, structured exercise intervention, repeated sprint abilities, neuromuscular training

Soccer is a sport prone to injuries with a greater number of injuries occurring during competition (41.33 lesions per $1000 \mathrm{~h}$ ) than in training (6.02 lesions per $1000 \mathrm{~h}) .{ }^{1}$ Muscle injuries account for about a third of all injuries in professional soccer, ${ }^{2}$ and injuries to the hamstring muscle complex contributed to $37 \%$ of all noncontact injuries, with a recurrence rate between $13 \%$ and $17 \% .^{3}$ On an average, when a player suffers a hamstring strain injury, he/ she missed 18 days and 3 to 3.5 matches, ${ }^{4}$ with the number of days of layoff increasing based on injury severity. ${ }^{5}$

Sprinting and kicking are among the principal causes of sustaining a hamstring injury in professional soccer. ${ }^{4,6}$ Previous research suggests that there is an association between an increased risk of injury or reinjury and hip and knee biomechanical anomalies during maximal or submaximal sprinting, ${ }^{7}$ or during phases of the kick when the hamstring muscles are most active. ${ }^{8}$ Comparing the hamstrings muscles individually, the long head of the biceps femoris experiences the greatest musculotendinous strain with respect to its length, ${ }^{9}$ thus presenting the highest risk of muscle injury. ${ }^{10}$

As a consequence of the high incidence, there have been many validated posthamstring strain injury rehabilitation models

Jiménez-Rubio, Navandar, and Rivilla-García are with the Departamento de Deportes, Facultad de Ciencias de la Actividad Física y del Deporte, INEF, Universidad Politécnica de Madrid, Madrid, Spain. Paredes-Hernández is with the Faculty of Physical Activity and Sports Sciences, Camilo José Cela University, Madrid, Spain. Jiménez-Rubio is also with the Getafe CF, Getafe, Spain. Navandar is also with the Faculty of Sport Sciences, Universidad Europea de Madrid, Madrid, Spain. Navandar (archit.navandar@universidadeuropea.es) is corresponding author. proposed in the literature, principally based on evaluations and preventive and performance models in the clinical and analytical field. These include the Askling L-protocol, ${ }^{11}$ the active knee extension test, ${ }^{12}$ the active straight leg raise test, ${ }^{13}$ prone hip extension test, ${ }^{14}$ or the Nordic hamstring protocol. ${ }^{15,16}$ Other programs at a more functional level include foot catches, ${ }^{17}$ the single-leg bridge test, ${ }^{18}$ or those that include aspects of force at a neuromuscular level. ${ }^{19,20}$ There are programs that evaluate previously injured athletes on tests based on change of direction and sprinting, such as the 505 agility test or the $T$ test, although they do not specifically mention a previous hamstring strain injury, ${ }^{21}$ despite a majority of these injuries occurring during maximal or submaximal sprinting. ${ }^{22}$

Epidemiological research shows an increase in hamstring strain injuries by $4 \%$ every year in elite male soccer teams in Europe. ${ }^{3}$ The exact cause for this is not clear. This could be due to a variety of factors. There have been changes in the demands of the game, with greater loads in recent years, for example, there were 25.27 (7.3) sprints per match registered in the 2013-2014 Spanish La Liga season, ${ }^{23}$ compared with 17.3 (7.7) sprints per match registered in the 2002-2004 seasons. ${ }^{24}$ Another possible cause cited in the literature is incomplete rehabilitation by forcing an early return to play. ${ }^{25}$ This implies that although the previously mentioned protocols, programs, and exercises have shown to be effective with the general athletic population, there appears to be a need for a soccer-specific rehabilitation program.

Such a program must have loads and movement profiles that represent match demands, which enable the player to not only recover from the injury at the earliest, but also return to play at the highest 
possible performance levels. Such a program must have a combination of indoor and on-field drills and involve functional tests that evaluate on-field performance parameters in relation to recovery. ${ }^{20,26}$ It ideally should be validated by a panel of experts in the field of strength and conditioning and rehabilitation in soccer to justify its practical use in a sport-specific context. Hence, the objective was to develop and validate a new, functional on-field program for the rehabilitation and readaptation of players after a hamstring strain injury through a panel of experts; and determine the usefulness of this program through its application in professional soccer players.

\section{Methods}

\section{Study Design}

A prospective, longitudinal rehabilitation and readaptation program following a hamstring strain injury consisting of 13 items was designed. This program was validated by a panel of experts, and then applied to 19 male soccer players to determine the time taken to return to play.

\section{Participants}

Fifteen strength and conditioning and rehabilitation fitness coaches (age: $37.40[2.70]$ y) participated as experts in the validation study. They had a professional experience of 15.40 (1.57) years in elite clubs and national teams in England, France, Russia, and Spain (Table 1).
The players $(n=19$, age $=24.23[5.36] \mathrm{y}$; height $=179.87$ [7.21] $\mathrm{cm}$; mass $=74.78[4.09] \mathrm{kg}$ ) volunteered to participate in the study and the rehabilitation program was explained to them and the staff of the clubs they belonged to. The inclusion criteria were (1) belonging to a professional soccer club in the first division between 2015 and 2018 and (2) having suffered a medically diagnosed grade II hamstring strain injury (using ultrasound and magnetic resonance imaging). ${ }^{27}$ The exclusion criteria were the player suffered an illness that implied an alteration in the rehabilitation. The nationalities of players were Spain $(n=12)$, Germany $(n=1)$, Serbia $(n=1)$, Brazil $(n=1)$, Uruguay $(n=2)$, Colombia $(\mathrm{n}=1)$, and Argentina $(\mathrm{n}=1)$.

\section{Procedure}

The experts were sent the following program to assess:

A previously uninjured soccer player having suffered a grade II, noncontact injury to the intramuscular myotendinous junction proximal of biceps femoris would be subjected to the rehabilitation and readaptation program. This injury is the most common type of a hamstring strain injury. ${ }^{28}$ The injury would have to be clinically diagnosed and confirmed by magnetic resonance imaging and/or musculoskeletal ultrasound, and initially treated with percutaneous needle electrolysis therapy ${ }^{29}$ on the second day following the injury. Before subjecting the player to the on-field program (day 8, postinjury), the player would have to undergo sessions in the gym focusing on achieving a full range of motion in the hip

\section{Table 1 Profile of the Panel of Experts Consisting of Strength and Conditioning Coaches and Rehabilitation Fitness Coaches}

\begin{tabular}{|c|c|c|}
\hline \multicolumn{3}{|l|}{ Highest academic qualifications } \\
\hline Degree & Number & $\%$ \\
\hline $\mathrm{PhD}$ & 8 & 53.33 \\
\hline Masters & 4 & 26.66 \\
\hline Graduate (sports science) & 3 & 20 \\
\hline \multicolumn{3}{|l|}{ Other complementary academic qualifications } \\
\hline Physiotherapist (graduate) & 4 & 26.6 \\
\hline Master's in rehabilitation + physiotherapy & 3 & 20 \\
\hline Master's in personal training + Master's in rehabilitation & 6 & 40 \\
\hline No complementary qualifications & 2 & 13.33 \\
\hline \multicolumn{3}{|l|}{ Soccer-specific coaching licenses } \\
\hline Union of European Football Associations (UEFA) Pro & 3 & 20 \\
\hline UEFA A & 4 & 26.66 \\
\hline UEFA B & 3 & 20 \\
\hline Without coaching license & 5 & 33.33 \\
\hline \multicolumn{3}{|l|}{ Experience with injured players } \\
\hline As strength and conditioning coaches $>10$ seasons & 2 & 13.33 \\
\hline As rehabilitation and strength and conditioning coaches for $10-15$ seasons with elite athletes & 3 & 20 \\
\hline As rehabilitation and strength and conditioning coaches $>15$ seasons with elite athletes & 10 & 66.66 \\
\hline \multicolumn{3}{|l|}{ Cumulative experience in career (titles) } \\
\hline Championship & Seasons & Titles \\
\hline UEFA Champions League & 3 & 2 \\
\hline UEFA Europa League & 14 & 1 \\
\hline First division & 211 & 5 leagues +3 cups \\
\hline Second division & 5 & \\
\hline
\end{tabular}


and knee, ${ }^{30-32}$ and performing controlled static and dynamic drills to strengthen the lower limbs (Figure 1). ${ }^{30}$

The players would then perform 13 on-field items of the rehabilitation and readaptation program (Table 2) in a progressive manner, which are arranged in an increasing order of complexity. When the player completes each of the 13 items successfully, he/ she would be declared to be fit to train with the group in the same conditions as his/her uninjured teammates. If the player could not complete all the items on a given day, he/she would train the uninjured zones in the rest of the training session.

\section{Statistical Analysis}

To validate the rehabilitation and readaptation program, the items (Table 2) were sent to 15 experts. The experts were asked to rate

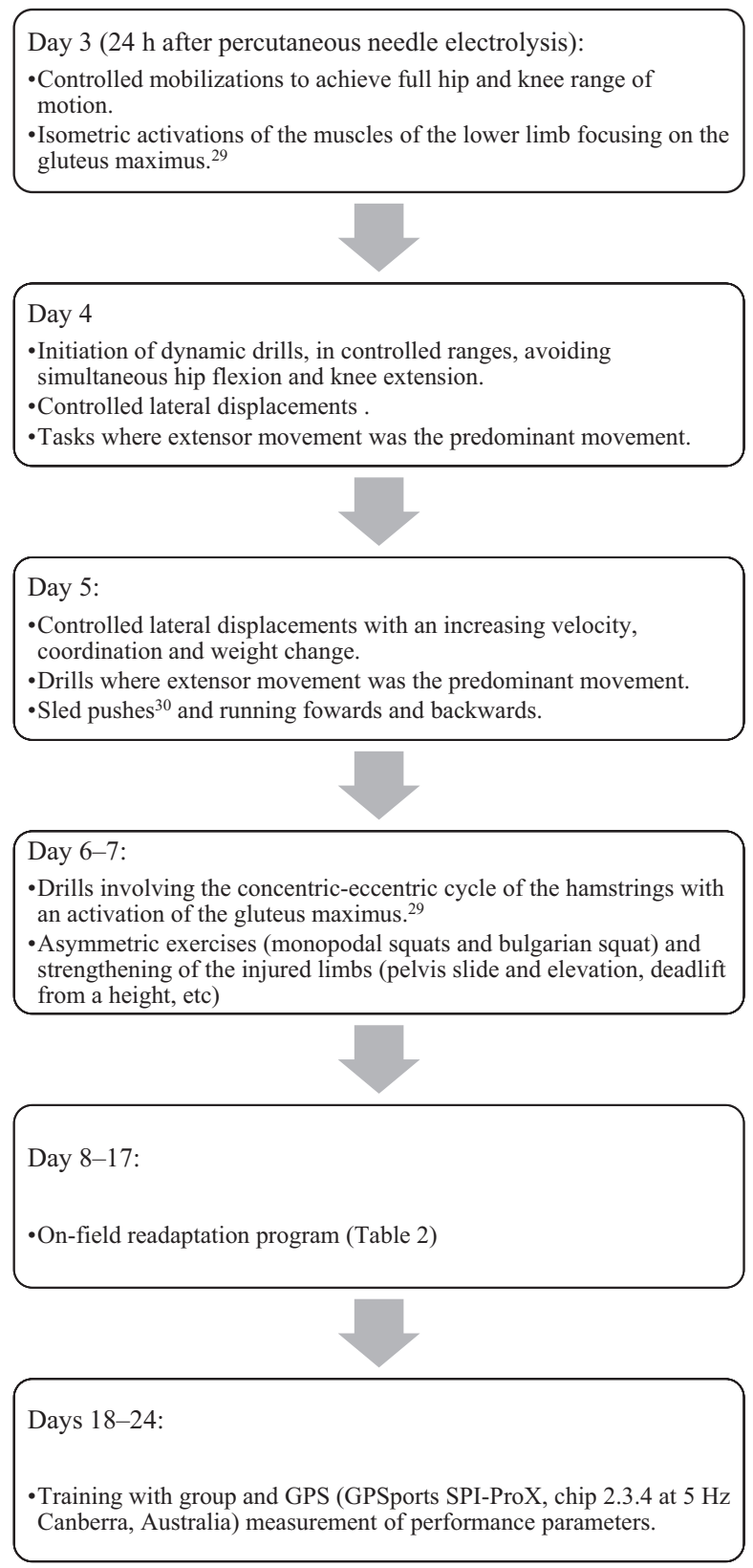

Figure 1 - The rehabilitation program to be followed by the injured players from the diagnosis of the injury until return to play. each item on a 5-point Likert-type scale, where the lowest possible rating $(n=1)$ corresponded to very poor relevance and the highest possible rating $(n=5)$ corresponded to very high relevance. The coefficient of content validation was calculated using Aiken's V, and its $95 \%$ confidence intervals were also determined. ${ }^{37} \mathrm{~A}$ minimum score of 0.75 was needed for an item to be valid. ${ }^{37}$ The calculations were carried out using Microsoft Excel 2016 (Microsoft®, Redmond, WA).

\section{Application of the Program}

The rehabilitation and readaptation program was applied to 19 male professional players of the Spanish first division. The number of days between the injury and the player's return to competition was counted.

\section{Results}

All 13 items of the rehabilitation and readaptation program were determined to be valid, as the quantitative values given by the panel of 15 experts were very high, and were reflected in the values of Aiken's V (Table 3). Players who had suffered a grade 2 hamstring strain injury returned to play competitively in 22.42 (2.32) days after undergoing this program, and did not suffer a reinjury in 6 months following return to play.

\section{Discussion}

In this study, a 13-item training program for the rehabilitation and readaptation phase following an injury to the hamstring muscle complex was proposed for professional soccer players and validated by a panel of experts. This is the first program to quantify onfield rehabilitation and readaptation following an injury to the hamstring muscle group in soccer and be validated by a panel of experts in the field of strength and conditioning and rehabilitation. The high scores obtained for the values of Aiken's V for all the 13 items confirm the relevance of this program for the intended domain and the results obtained as a consequence are meaningful. ${ }^{37}$

The drills incorporated progressively increasing loads that not only enabled the players to adapt to the increasing demands of present-day soccer, ${ }^{23}$ but also protected them from a subsequent reinjury in the 6 months following return to play. In Australian Rules Football, a recent recent study has demonstrated that increasing training loads increased return to play time, and potentially protects an athlete from a subsequent reinjury. ${ }^{38}$ In this study, the number of days of layoff between competitions was within the 21 to 27 days reported for a grade II hamstring strain injury. ${ }^{38}$ One needs to keep in mind that the data reported here represent the return to play time, which depends largely on the league calendar and scheduling of the international breaks.

When an athlete suffers an injury, the return to play process aims to reeducate the on-field movements that the player performed efficiently previously and that have been hindered by the appearance of the injury. This has been defined as functional sports reeducation ${ }^{39}$ and refers to the entire process that begins from the onset of the injury to the complete return to play. An inadequate rehabilitation may cause persistent weakness in the injured muscle, reduce extensibility of the musculotendinous unit, and cause an altered neuromuscular control resulting in adaptive changes in the biomechanics and motor patterns of sporting movements. ${ }^{25}$ The 13 items, designed to be followed in a progressive manner after the 


\section{Table 2 The 13 Items of the Rehabilitation and Readaptation and Retraining Programs}

\begin{tabular}{|c|c|c|}
\hline No. & Description & Total time \\
\hline 1 & $\begin{array}{l}\text { Lateral displacements, alternative single-legged dead lifts, and controlled landing drills with lowering of the centre of gravity } \\
\text { at controlled velocities and leverages of the stretch-shortening cycle of the hamstrings. }{ }^{19,31}\end{array}$ & $3 \mathrm{~min}$ \\
\hline 2 & Coordinated soccer-specific controlled drills at the static and dynamic level: ball control, passing, dribbling, and kicking. & $6 \mathrm{~min}$ \\
\hline 3 & $\begin{array}{l}\text { Six discontinuous aerobic running drills (under } 14 \mathrm{~km} / \mathrm{h} \text { ) and reeducation of frontal acceleration patterns }(7 \mathrm{~s} \text { of acceleration } \\
\text { and } 3 \mathrm{~s} \text { of deceleration). }\end{array}$ & $1 \mathrm{~min}$ \\
\hline 4 & $\begin{array}{l}\text { Three sets of soccer-specific agility and coordination drills (with and without a ball in the same action) followed by a return to } \\
\text { the initial position walking. }\end{array}$ & $1 \min 10 \mathrm{~s}$ \\
\hline 5 & $\begin{array}{l}\text { Three sets of intermittent, adapted high-speed running drills }(15 \mathrm{~s} \text { at velocities }>14 \mathrm{~km} / \mathrm{h} \text {, and } 10 \mathrm{~s}<14 \mathrm{~km} / \mathrm{h}) \text { in aerobic and } \\
\text { anaerobic conditions }(70-90 \mathrm{~s} \text { per set). }\end{array}$ & $\begin{array}{l}\min 30 \mathrm{~s}-4 \mathrm{~min} \\
30 \mathrm{~s}\end{array}$ \\
\hline 6 & $\begin{array}{l}\text { Four sets of } 4 \text { repetitive actions (without uncertainty) with change of direction and deceleration (total displacements of } \\
8-14 \mathrm{~m} \text {, total time }<12 \mathrm{~s} \text { ), followed by shooting at a minigoal } 12 \mathrm{~m} \text { away. Rest of } 15 \mathrm{~s} \text { between sets. }\end{array}$ & $1 \min 30 \mathrm{~s}$ \\
\hline 7 & $\begin{array}{l}\text { Three high-intensity runs with aerobic capacity at } 100 \%-120 \% \text { maximum aerobic velocity of the athlete for } 80 \mathrm{~s} \text {, followed by } \\
40 \mathrm{~s} \text { rest. }\end{array}$ & $4 \mathrm{~min}$ \\
\hline 8 & $\begin{array}{l}\text { Four tractions of } 20 \mathrm{~m} \text { with sled towing (with a 10-kg disk) in the 1-2-1 sequence with } 8 \mathrm{~s} \text { of rest between sequences, }{ }^{33} \text { with an } \\
\text { optional kicking drill after the sets. }\end{array}$ & $52 \mathrm{~s}$ \\
\hline 9 & $\begin{array}{l}\text { Four sets of soccer-specific actions (with and without a ball) including } 8 \text { RSA drills without uncertainty (distance }>14 \mathrm{~m} \text { ) } \\
\text { with patterns of deceleration/stopping, change of direction, pivoting, cushioning, and repetition. }{ }^{21} \text { Rest of } 12 \mathrm{~s} \text { between sets. }\end{array}$ & $1 \min 40 \mathrm{~s}$ \\
\hline 10 & $\begin{array}{l}\text { One set of } 6 \text { DRSA followed by another set of } 4 \text { DRSA drills. }{ }^{34} \text { Each DRSA was carried out at a } 40-\mathrm{m}+40-\mathrm{m} \text { distance } \\
(8+8 \mathrm{~s}) \text { at velocities } \geq 18 \mathrm{~km} / \mathrm{h} \text {. There was a rest of } 16 \mathrm{~s} \text { between DRSA, and } 1^{\prime} 45^{\prime \prime} \text { on completion of each set. }\end{array}$ & $8 \min 18 \mathrm{~s}$ \\
\hline 11 & $\begin{array}{l}\text { Three sets of soccer-specific drills, including change of direction with uncertainty, }{ }^{35} \text { and RSA. Each drill had } 4 \text { subdrills, with } \\
\text { the total time of the set varied between } 22 \text { and } 25 \mathrm{~s} \text {. Rest of } 12 \mathrm{~s} \text { between sets. }\end{array}$ & $1 \min 36 \mathrm{~s}$ \\
\hline 12 & $\begin{array}{l}\text { Physical-tactical readaptation through soccer-specific actions between } 6 \text { and } 8 \text { min, including } 4 \text { sprints (at velocities between } \\
28 \text { and } 30 \mathrm{~km} / \mathrm{h} \text { ) each with a duration of } 8 \mathrm{~s} \text {, replicating situations prior to injury based on player's position. }{ }^{36}\end{array}$ & $6-8 \mathrm{~min}$ \\
\hline 13 & $\begin{array}{l}\text { Four drills involving actions similar to injury mechanism at high velocities without external contact. Each drill lasted a } \\
\text { maximum of } 15 \mathrm{~s} \text { with an incomplete recovery }(<30 \mathrm{~s}) \text {. }\end{array}$ & $1 \min 47 \mathrm{~s}$ \\
\hline
\end{tabular}

Abbreviations: DRSA, double repeated sprint ability; RSA, repeated sprint ability.

Table 3 The Item-Content Relevance Score for All the 13 Items as Per the 15 Experts, Aiken's V, and the $95 \%$ Cls of Aiken's V

\begin{tabular}{|c|c|c|c|c|c|c|c|}
\hline Item & 1 & 2 & 3 & 4 & 5 & Mean & Aiken's V $(95 \% \mathrm{Cl})$ \\
\hline 1 & 1 & 1 & 2 & 2 & 9 & 4.13 & $0.78(0.63-0.88)$ \\
\hline 2 & & & 3 & 2 & 10 & 4.47 & $0.87(0.73-0.94)$ \\
\hline 3 & & & 1 & 2 & 12 & 4.73 & $0.93(0.81-0.98)$ \\
\hline 4 & & & 2 & 2 & 11 & 4.60 & $0.90(0.77-0.96)$ \\
\hline 5 & & & 2 & 3 & 10 & 4.53 & $0.88(0.75-0.95)$ \\
\hline 6 & & & & 1 & 14 & 4.93 & $0.98(0.88-1)$ \\
\hline 7 & & & 1 & 2 & 12 & 4.73 & $0.93(0.81-0.98)$ \\
\hline 8 & & & 1 & 2 & 12 & 4.73 & $0.93(0.81-0.98)$ \\
\hline 9 & & & 1 & 1 & 13 & 4.80 & $0.95(0.83-0.99)$ \\
\hline 10 & & 1 & 1 & 3 & 10 & 4.47 & $0.87(0.73-0.94)$ \\
\hline 11 & & & & 2 & 13 & 4.87 & $0.97(0.86-0.99)$ \\
\hline 12 & & & 2 & 2 & 11 & 4.60 & $0.9(0.77-0.96)$ \\
\hline 13 & & & & 2 & 13 & 4.87 & $0.97(0.86-0.99)$ \\
\hline
\end{tabular}

Abbreviation: CI, confidence interval. Note: The ratings of the 15 experts varied on a scale from 1 to 5 , where 1 corresponded to very poor relevance and 5 corresponded to very high relevance.

successful completion of each, included drills and actions that were very similar to the soccer-specific movements carried out during training or matches, in an environment which was familiar for the soccer player. It integrated various aspects of repeated sprint abilities, retraining and reeducation of biomechanical patterns, and neuromuscular control of the core and lower limbs.
The highest ratings ( $>0.9)$ were obtained for items $3,6,7,8,9$, 11 , and 13, which incorporated repeated sprint abilities ${ }^{40}$ and a reeducation and retraining of acceleration-deceleration patterns (with repeated changes of direction) ${ }^{41}$ involving movements specific to soccer (Tables 2 and 3 ) and the player positions. ${ }^{42}$ Such actions are very common in soccer, where a player on an average performs 
between 3 and 40 sprints in a competitive game. ${ }^{24}$ They have increasingly formed a part of soccer training, ${ }^{43}$ testing for return to play criteria postsoccer injuries, ${ }^{40}$ and in rehabilitation in the case of a previous hamstring strain injury. ${ }^{44}$ All of these considerations have been introduced at the aerobic and anaerobic level in the validated training presented within this program in relation to return to play.

Drills involving movements similar to the injury mechanism, focusing on agility and coordination, were incorporated throughout the 13 items. Previous research has shown that the eccentric control of the knee as the hip flexed in movements where high forces were generated was important. ${ }^{45,46}$ Such movements can be seen during the terminal swing while sprinting at submaximal and maximal velocities, ${ }^{22}$ or in the follow-through phase following kicking. ${ }^{8}$ These studies have shown that there are biomechanical differences between the previously injured and uninjured limbs in these drills. A deficiency in the previously injured limb might be one of the reasons as to why the hamstring muscle complex has a high reinjury rate. The rehabilitation program proposed the included drills that focused on the reeducation of these general and soccerspecific movement patterns with the complexity increasing successively in the items.

Neuromuscular control also formed an important part of the program. Given the dual innervation of the biceps femoris, ${ }^{47}$ a possible asynchrony in the coordination may be the reason why the biceps femoris is the most commonly injured muscle of the hamstring muscle complex. ${ }^{5}$ Neuromuscular training has shown to be effective in reducing the risk of knee injuries, ${ }^{48}$ and an adequate proximal muscle control has been shown to be important during maximal sprinting to decrease the hamstring injury risk. ${ }^{19,31}$ In addition, a deficit of neuromuscular control in the hamstring muscle complex has been shown to be a risk factor for an anterior cruciate ligament tear. ${ }^{49}$ Therefore, the program combined various drills with and without uncertainty to reeducate motor patterns.

This program has a very high relevance in professional soccer as it contains 13 on-field items, the successful completion of all determining that the player is fit to return to play. These involve drills that are very similar to actions the players execute during matches and training. The drills also emphasize reeducation of the different injury mechanisms, in an environment very similar to where they occur, and as a result can go a long way in preventing a reinjury to the hamstring muscle complex. Although the program was applied to 19 professional players and no subsequent reinjuries were reported, comparing preinjury and postinjury data during matches with the help of Global Positioning System data could demonstrate the improvement in the players and how effective this program can be.

\section{Conclusion}

The program proposed for the rehabilitation and readaptation phase following an injury to the hamstring muscle complex was determined to be valid by the panel of experts, given its soccer-specific context and that the entire program was carried out on the field. This program has the potential to help an injured player adapt to real-match conditions in the rehabilitation phase by including drills that are very similar to those that the player carries out on the field, and this was evident with the practical application of the program.

\section{Acknowledgment}

The authors have no conflicts of interest to disclose.

\section{References}

1. Noya Salces J, Gómez-Carmona PM, Gracia-Marco L, MolinerUrdiales D, Sillero-Quintana M. Epidemiology of injuries in first division Spanish football. J Sports Sci. 2014;32(13):1263-1270. PubMed ID: 24787731 doi:10.1080/02640414.2014.884720

2. Ekstrand J, Hägglund M, Waldén M. Epidemiology of muscle injuries in professional football. Am J Sports Med. 2011;39(6): 1226-1232. PubMed ID: 21335353 doi:10.1177/0363546510395879

3. Ekstrand J, Waldén M, Hägglund M. Hamstring injuries have increased by $4 \%$ annually in men's professional football, since 2001: a 13-year longitudinal analysis of the UEFA Elite Club injury study. Br J Sports Med. 2016;50(12):731-737. PubMed ID: 26746908 doi:10.1136/bjsports-2015-095359

4. Woods C, Hawkins RD, Maltby S, Hulse M, Thomas A, Hodson A. The football association medical research programme: an audit of injuries in professional football—analysis of hamstring injuries. $\mathrm{Br} \mathrm{J}$ Sports Med. 2004;38(1):36-41. PubMed ID: 14751943 doi:10.1136/ bjsm.2002.002352

5. Beltran L, Ghazikhanian V, Padron M, Beltran J. The proximal hamstring muscle-tendon-bone unit: a review of the normal anatomy, biomechanics, and pathophysiology. Eur J Radiol. 2012; 81(12):3772-3779. PubMed ID: 21524864 doi:10.1016/j.ejrad. 2011.03.099

6. Liu H, Garrett WE, Moorman CT, Yu B. Injury rate, mechanism, and risk factors of hamstring strain injuries in sports: a review of the literature. J Sport Health Sci. 2012;1(2):92-101. doi:10.1016/j.jshs. 2012.07.003

7. Lee MJC, Reid SL, Elliott BC, Lloyd DG. Running biomechanics and lower limb strength associated with prior hamstring injury. Med Sci Sports Exerc. 2009;41(10):1942-1951. PubMed ID: 19727017 doi:10.1249/MSS.0b013e3181a55200

8. Navandar A, Veiga S, Torres G, Chorro D, Navarro E. A previous hamstring injury affects kicking mechanics in soccer players. J Sports Med Phys Fitness. 2018. PubMed ID: 29327823 doi:10.23736/ S0022-4707.18.07852-0

9. Schache AG, Dorn TW, Blanch PD, Brown NA, Pandy MG. Mechanics of the human hamstring muscles during sprinting. Med Sci Sports Exerc. 2012;44(4):647-658. PubMed ID: 21912301 doi:10.1249/MSS.0b013e318236a3d2

10. Picerno $P$. The hamstrings-injury-mechanism debate: are we close to an agreement? J Sport Rehabil. 2017;26(2):120-121. PubMed ID: 27992303 doi:10.1123/jsr.2016-0145

11. Askling CM, Tengvar M, Thorstensson A. Acute hamstring injuries in Swedish elite football: a prospective randomised controlled clinical trial comparing two rehabilitation protocols. Br J Sports Med. 2013; 47(15):953-959. PubMed ID: 23536466 doi:10.1136/bjsports-2013092165

12. Reurink G, Goudswaard GJ, Oomen HG, et al. Reliability of the active and passive knee extension test in acute hamstring injuries. Am J Sports Med. 2013;41(8):1757-1761. PubMed ID: 23735425 doi:10. $1177 / 0363546513490650$

13. Liebenson C, Karpowicz AM, Brown SH, Howarth SJ, McGill SM. The active straight leg raise test and lumbar spine stability. $P M R$. 2009;1(6):530-535. PubMed ID: 19627942 doi:10.1016/j.pmrj. 2009.03.007

14. Chance-Larsen K, Littlewood C, Garth A. Prone hip extension with lower abdominal hollowing improves the relative timing of gluteus maximus activation in relation to biceps femoris. Man Ther. 2010;15(1):61-65. PubMed ID: 19679506 doi:10.1016/j.math.2009. 07.001 
15. Mjolsnes R, Arnason A, Osthagen T, Raastad T, Bahr R. A 10-week randomized trial comparing eccentric vs. concentric hamstring strength training in well-trained soccer players. Scand J Med Sci Sports. 2004;14(5):311-317. PubMed ID: 15387805 doi:10.1046/j. 1600-0838.2003.367.x

16. Opar DA, Williams MD, Timmins RG, Hickey J, Duhig SJ, Shield AJ. Eccentric hamstring strength and hamstring injury risk in Australian footballers. Med Sci Sports Exerc. 2015;47(4):857-865. PubMed ID: 25137368 doi:10.1249/MSS.0000000000000465

17. Sherry MA, Best TM. A comparison of 2 rehabilitation programs in the treatment of acute hamstring strains. J Orthop Sports Phys Ther. 2004;34(3):116-125. PubMed ID: 15089024 doi:10.2519/jospt.2004. 34.3.116

18. Freckleton G, Cook J, Pizzari T. The predictive validity of a single leg bridge test for hamstring injuries in Australian rules football players. Br J Sports Med. 2014;48(8):713-717. PubMed ID: 23918443 doi:10.1136/bjsports-2013-092356

19. Mendiguchia J, Martinez-Ruiz E, Edouard P, et al. A multifactorial, criteria-based progressive algorithm for hamstring injury treatment. Med Sci Sports Exerc. 2017;49(7):1482-1492. PubMed ID: 28277402 doi:10.1249/MSS.0000000000001241

20. Taberner M, Cohen DD. Physical preparation of the football player with an intramuscular hamstring tendon tear: clinical perspective with video demonstrations. Br J Sports Med. 2018;52(19):1275-1278. PubMed ID: 29724748 doi:10.1136/bjsports-2017-098817

21. Stewart PF, Turner AN, Miller SC. Reliability, factorial validity, and interrelationships of five commonly used change of direction speed tests. Scand J Med Sci Sports. 2014;24(3):500-506. PubMed ID: 23176602 doi:10.1111/sms.12019

22. Chumanov ES, Heiderscheit BC, Thelen DG. Hamstring musculotendon dynamics during stance and swing phases of high-speed running. Med Sci Sports Exerc. 2011;43(3):525-532. PubMed ID: 20689454 doi:10.1249/MSS.0b013e3181f23fe8

23. Rivilla-García J, Calvo LC, Jiménez-Rubio S, et al. Characteristics of very high intensity runs of soccer players in relation to their playing position and playing half in the 2013-14 Spanish La Liga Season [published online ahead of print September, 2018]. J Hum Kinet. doi:10.2478/hukin-2018-0058

24. Di Salvo V, Baron R, Tschan H, Calderón Montero FJ, Bachl N, Pigozzi F. Performance characteristics according to playing position in elite soccer. Int J Sports Med. 2007;28:222-227. PubMed ID: 17024626 doi:10.1055/s-2006-924294

25. Erickson LN, Sherry MA. Rehabilitation and return to sport after hamstring strain injury. J Sport Health Sci. 2017;6(3):262-270. PubMed ID: 30356646 doi:10.1016/j.jshs.2017.04.001

26. Pfirrmann D, Herbst M, Ingelfinger P, Simon P, Tug S. Analysis of injury incidences in male professional adult and elite youth soccer players: a systematic review. J Athl Train. 2016;51(5):410-424. PubMed ID: 27244125 doi:10.4085/1062-6050-51.6.03

27. Chan O, Del Buono A, Best TM, Maffulli N. Acute muscle strain injuries: a proposed new classification system. Knee Surg Sports Traumatol Arthrosc. 2012;20(11):2356-2362. PubMed ID: 22773066 doi:10.1007/s00167-012-2118-Z

28. Heiderscheit BC, Sherry MA, Silder A, Chumanov ES, Thelen DG. Hamstring strain injuries: recommendations for diagnosis, rehabilitation, and injury prevention. J Orthop Sports Phys Ther. 2010;40(2):67-81. PubMed ID: 20118524 doi:10.2519/jospt.2010.3047

29. Valera-Garrido F, Minaya-Muñoz F, Medina-Mirapeix F. Ultrasoundguided percutaneous needle electrolysis in chronic lateral epicondylitis: short-term and long-term results. Acupunct Med. 2014;32(6):446454. PubMed ID: 25122629 doi:10.1136/acupmed-2014-010619
30. Bosch F, Ijzerman J. Running mechanics in injury prevention and performance. In: Joyce D, Lewindon D, eds. Sports Injury Prevention and Rehabilitation. Integrating Medicine and Science for Performance Solutions. Abingdon-on-Thames, UK: Routledge; 2016:106120.

31. Schuermans J, Danneels L, Van Tiggelen D, Palmans T, Witvrouw E. Proximal neuromuscular control protects against hamstring injuries in male soccer players. Am J Sports Med. 2017;45(6):1315-1325. PubMed ID: 28263670 doi:10.1177/0363546516687750

32. Morin JB, Petrakos G, Jimenez-Reyes P, Brown SR, Samozino P, Cross MR. Very-heavy sled training for improving horizontal-force output in soccer players. Int J Sports Physiol Perform. 2017;12(6): 840-844. PubMed ID: 27834560 doi:10.1123/ijspp.2016-0444

33. Martínez-Valencia MA, Romero-Arenas S, Elvira JLL, GonzálezRavé JM, Navarro-Valdivielso F, Alcaraz PE. Effects of sled towing on peak force, the rate of force development and sprint performance during the acceleration phase. J Hum Kinet. 2015;46:139-148. PubMed ID: 26240657 doi:10.1515/hukin-2015-0042

34. Impellizzeri FM, Rampinini E, Castagna C, et al. Validity of a repeated-sprint test for football. Int J Sports Med. 2008;29(11):899905. PubMed ID: 18415931 doi:10.1055/s-2008-1038491

35. Fort-Vanmeerhaeghe A, Romero-Rodriguez D, Lloyd RS, Kushner A, Myer GD. Integrative neuromuscular training in youth athletes. part ii: strategies to prevent injuries and improve performance. Strength Cond J. 2016;38(4):9-27. doi:10.1519/SSC.0000000000000234

36. Paredes Hernández V, Martos Varela S, Romero Moraleda B. Propuesta de readaptación para la rotura del ligamento cruzado anterior en fútbol. Rev Int Cienc Deporte. 2011;11(43):573-591.

37. Penfield RD, Giacobbi JPR. Applying a score confidence interval to Aiken's item content-relevance index. Meas Phys Educ Exerc Sci. 2004;8(4):213-225. doi:10.1207/s15327841mpee0804_3

38. Stares J, Dawson B, Peeling P, et al. How much is enough in rehabilitation? High running workloads following lower limb muscle injury delay return to play but protect against subsequent injury. $J$ Sci Med Sport. 2018;21(10):1019-1024. PubMed ID: 29764731 doi:10. 1016/j.jsams.2018.03.012

39. Lalín C, Peirau X. La reeducación funcional deportiva. [The functional sporting reeducation]. In: Nacleiro F, ed. Entrenamiento deportivo: fundamentos y aplicaciones en diferentes deportes. Sports training: fundamenals and applications in different sports. Madrid: Médica Panamericana; 2011:419-429.

40. Padulo J, Attene G, Ardigo LP, et al. Can a repeated sprint ability test help clear a previously injured soccer player for fully functional return to activity? a pilot study. Clin J Sport Med. 2017;27(4):361-368. PubMed ID: 27428681 doi:10.1097/JSM.0000000000000368

41. Morin JB, Gimenez P, Edouard P, et al. Sprint acceleration mechanics: the major role of hamstrings in horizontal force production. Front Physiol. 2015;6:404. PubMed ID: 26733889 doi:10.3389/fphys. 2015.00404

42. Mallo J, Mena E, Nevado F, Paredes V. Physical demands of top-class soccer friendly matches in relation to a playing position using global positioning system technology. J Hum Kinet. 2015;47(1):179-188. PubMed ID: 26557202 doi:10.1515/hukin-2015-0073

43. Bishop D, Girard O, Mendez-Villanueva A. Repeated-sprint abilitypart II. Sports Med. 2011;41(9):741-756. PubMed ID: 21846163 doi:10.2165/11590560-000000000-00000

44. van der Horst N, Backx F, Goedhart EA, Huisstede BM. Return to play after hamstring injuries in football (soccer): a worldwide Delphi procedure regarding definition, medical criteria and decision-making. Br J Sports Med. 2017;51(22):1583-1591. PubMed ID: 28360143 doi:10.1136/bjsports-2016-097206 
45. Buckthorpe M, Gimpel M, Wright S, Sturdy T, Stride M. Hamstring muscle injuries in elite football: translating research into practice. $\mathrm{Br} \mathrm{J}$ Sports Med. 2018;52(10):628-629. PubMed ID: 29051167 doi:10. 1136/bjsports-2017-097573

46. Macdonald B, O’Neill J, Pollock N, Van Hooren B. The single-leg Roman chair hold is more effective than the Nordic hamstring curl in improving hamstring strength-endurance in Gaelic footballers with previous hamstring injury. J Strength Cond Res. 2018. PubMed ID: 29489726 doi:10.1519/JSC.0000000000002526

47. Clark R, Bryant A, Culgan JP, Hartley B. The effects of eccentric hamstring strength training on dynamic jumping performance and isokinetic strength parameters: a pilot study on the implications for the prevention of hamstring injuries. Phys Ther Sport. 2005;6:67-73. doi:10.1016/j.ptsp.2005.02.003

48. Myer GD, Chu DA, Brent JE, Hewett TE. Trunk and hip control neuromuscular training for the prevention of knee joint injury. Clin Sports Med. 2008;27(3):425-448. PubMed ID: 18503876 doi:10. 1016/j.csm.2008.02.006

49. Opar DA, Serpell BG. Is there a potential relationship between prior hamstring strain injury and increased risk for future anterior cruciate ligament injury? Arch Phys Med Rehabil. 2014;95(2): 401-405. PubMed ID: 24121082 doi:10.1016/j.apmr.2013. 07.028 